\title{
ABRUPT CLINE FOR SEX CHROMOSOMES IN A HYBRID ZONE BETWEEN TWO SPECIES OF MICE
}

\author{
Priscilla K. Tucker, ${ }^{1.2}$ Richard D. Sage, ${ }^{3,4.6}$ John Warner, ${ }^{5}$ \\ Allan C. Wilson, ${ }^{3}$ ANd Eva M. EICHER' \\ 'The Jackson Laboratory, Bar Harbor, ME 04609 USA \\ ${ }^{2}$ Department of Biology and Museum of Zoology, University of Michigan, Ann Arbor, MI 48109 USA \\ ${ }^{3}$ Division of Biochemistry and Molecular Biology, University of California, \\ Berkeley, CA 94720 USA \\ ${ }^{4}$ Museum of Vertebrate Zoology, University of California, Berkeley, CA 94720 USA \\ ${ }^{5}$ Center for Statistical Consultation and Research, University of Michigan, \\ Ann Arbor, MI 48109 USA
}

\begin{abstract}
We compared the patterns of movement of sex chromosomal and autosomal loci along a $160 \mathrm{~km}$ transect across a zone of hybridization between $M$. domesticus and $M$. musculus in southern Germany and western Austria using seven genetic markers. These included one Y-specific DNA sequence $(Y B 10)$, two X-specific loci $(D X W a s 68$ and $D X W a s 31)$, and four autosomal isozyme loci $(E s-10, E s-1, M p i-1$, and $N p-l)$. Random effects logistic regression analysis enabled us to examine the relationship between $M$. domesticus allele frequency and geographic distance from the western edge of the hybrid zone and allowed statistical evaluation of differences in cline midpoint and width among loci. More limited movement was observed for all three sex chromosomal markers across the zone compared with three of the four autosomal markers. If differential movement reflects fitness differences of specific alleles (or alleles at closely linked loci) on a hybrid background, then alleles that move to a limited extent across a hybrid zone may contribute to hybrid breakdown between two species. The limited flow of both $\mathrm{X}$ - and $\mathrm{Y}$-specific alleles suggest that sex chromosomes have played an important role in Mus speciation.
\end{abstract}

Key words. - Hybrid zone, logistic regression, Mus, sex chromosomes.

Received August 28, 1990. Accepted February 4, 1992.

Two approaches have been used to analyze the genetic basis of species differences. The first is to make crosses between two species and assess the degree of sterility or inviability in $F_{1}$ and backcross individuals. This approach has been used in studies on the genetic basis of species differences in Drosophila (Coyne, 1985; Vigneault and Zouros, 1986; Orr, 1987). The second approach is to analyze individuals in a region where two species meet in nature. By studying the nature of genetic differences across a hybrid zone one may gain insight into the kinds of genetic differences involved in species divergence (Barton and Hewitt, 1985; Hewitt, 1988, 1989). The underlying assumption for this type of study is that differential movement of alleles reflects fitness differences of specific alleles or alleles at closely linked loci when placed on a hybrid background. For example, alleles that move extensively across the zone are presumably

\footnotetext{
${ }^{6}$ Present address: Division of Biological Sciences, University of Missouri, Columbia, MO 65211 USA.
}

neutral or selectively advantageous on a hybrid background whereas alleles that move to a limited extent are assumed to be selected against on a hybrid background. The latter type of allele may contribute to hybrid breakdown between two species and may play a role in species divergence.

Laboratory studies on the genetic basis of species differences in Drosophila as well as a number of other species have shown that the $\mathrm{X}$ and $\mathrm{Y}$ chromosomes play a major role in $F_{1}$ hybrid sterility and inviability in both males and females and thus may be major factors in speciation (reviewed in Coyne and Orr, 1989). Field studies have documented limited movement of the $\mathrm{X}$ chromosome across hybrid zones in three insect taxa (Moran, 1979; Hewitt et al., 1988; Hagen, 1990; Sperling and Spence, 1991) and limited movement of one Y-specific allele across a hybrid zone in a single mammalian species (Vanlerberghe et al., 1986, 1988b).

We have investigated the potential role of both the $\mathrm{X}$ and $\mathrm{Y}$ chromosomes in reproductive isolation in a mammal by com- 
paring the movement of three sex chromosomal loci and four autosomal loci across a hybrid zone between two species of European house mouse, Mus domesticus and $M$. musculus. The $M$. domesticus $-M$. musculus hybrid zone extends from Denmark to Bulgaria through central and southern Europe. Genetic studies across this zone in Denmark (Hunt and Selander, 1973; Ferris et al., 1983; Vanlerberghe et al., 1986, $1988 a, 1988 b$ ), West Germany and Austria (Sage et al., 1986a, 1986b), and Bulgaria (Vanlerberghe et al., 1986, 1988b) have documented restricted genetic exchange between $M$. domesticus and $M$. musculus. Our study was conducted along the previously described $160 \mathrm{~km}$ east-west transect in West Germany and Austria (Sage et al., 1986a). We used the statistical techniques of fixed effects and random effects logistic regression to analyze cline shape for individual loci within the hybrid zone. We determined that random effects logistic regression fits the data whereas fixed effects logistic regression does not. Using the random effects logistic model, estimates of cline shape were determined. The results show that both $\mathrm{X}$ - and $Y$-specific alleles move to a limited extent across the zone in contrast to alleles from three of the four autosomal loci. Our study also supports the analysis of Vanlerberghe et al. $(1986,1988 b)$ who found little movement of the $\mathrm{Y}$ chromosome across the hybrid zone between $M$. domesticus and $M$. musculus in Denmark and Bulgaria.

\section{Materials and Methods}

Mice.-Mus domesticus, $M$. musculus, and hybrid $(M$. domesticus $\times M$. musculus) mice were collected from 40 sites at 30 localities along a $160 \mathrm{~km}$ east-west transect across the hybrid zone in southern Germany and western Austria (Sage et al., 1986a; Fig. 1). A total of 303 mice (128 males and 175 females) was used for the study (Table 1 , Appendix). Specific collecting localities are listed in Figure 1. Voucher specimens are deposited in the Museum of Vertebrate Zoology (MVZ), University of California, Berkeley, CA.

DNA Probes. - Probe $\mathrm{pYB} 10$ is a 305 base pair sequence derived from the $\mathrm{Y}$ chromosome of the inbred mouse strain C57BL/ 10 and identifies YB10 (Y-specific B10-de- rived) sequences present in multiple copies (approximately 550) exclusively on the $\mathrm{Y}$ chromosome in $M$. musculus and $M$. domesticus (Eicher et al., 1989). Probe 68-36 is a $5.0 \mathrm{~kb}$ sequence that identifies the X-linked locus $D X$ Was68 (DNA segment, Chr. X, University of Washington-68) (Disteche et al., 1982, 1989). Approximately 50 copies of 68-36 sequences are present at the proximal end of the $\mathrm{X}$ chromosome (Disteche et al., 1985). Probe $31 \mathrm{~A}$ is a $1.5 \mathrm{~kb}$ single copy sequence that identifies the X-linked locus $D X$ Was 31 (DNA segment, Chr. X, University of Washington-31). 31A sequences are localized at the distal end of the X chromosome (Disteche et al., 1989). $D X W a s 68$ and $D X W a s 31$ are approximately $68 \mathrm{cM}$ apart (Disteche et al., 1989). Presumably, both these loci assort independently unless there is a fitness-reducing allele located between them. For ease of presentation the $D X W a s 68$ and $D X W a s 31$ loci are hereafter designated $X 1$ and $X 2$, respectively.

DNA Preparation. - High molecular weight genomic DNA was prepared from frozen tissue or from frozen nuclear pellets following the method of Jenkins et al. (1982) or a modification of this method (Tucker et al., 1989). Restriction enzyme digests of 10 $\mu \mathrm{g}$ of genomic DNA were performed following the procedures of the supplier (GIBCO BRL, Inc.) and the DNA fragments were separated by size in $1 \%$ agarose. DNA was transferred to Zeta-Probe nylon membranes (Bio-Rad) in $0.4 \mathrm{M} \mathrm{NaOH}$ overnight without pretreatment (Reed and Mann, 1985).

The $\mathrm{Y}$ chromosome probe was labeled with [a- $\left.{ }^{32} \mathrm{P}\right]-d C T P$ (Amersham) following Maniatis et al. (1982), using the $T_{4}$ polymerase kit supplied by BRL. The $\mathrm{X}$ chromosome probes were labeled with [a$\left.{ }^{32} \mathrm{P}\right]$-dCTP (Amersham or New England Nuclear) following Feinberg and Volgelstein (1983, 1984) using the random primer labeling kits supplied by Boehringer-Mannheim or Amersham. The specific activity of labeled DNA was greater than $0.5 \times 10^{9}$ $\mathrm{cpm} / \mu \mathrm{g}$.

Hybridization and autoradiography were performed as described in Tucker et al. (1989) with the following modifications. Nylon membranes hybridized with the $\mathrm{X}$ chromosome probes were rinsed twice in 


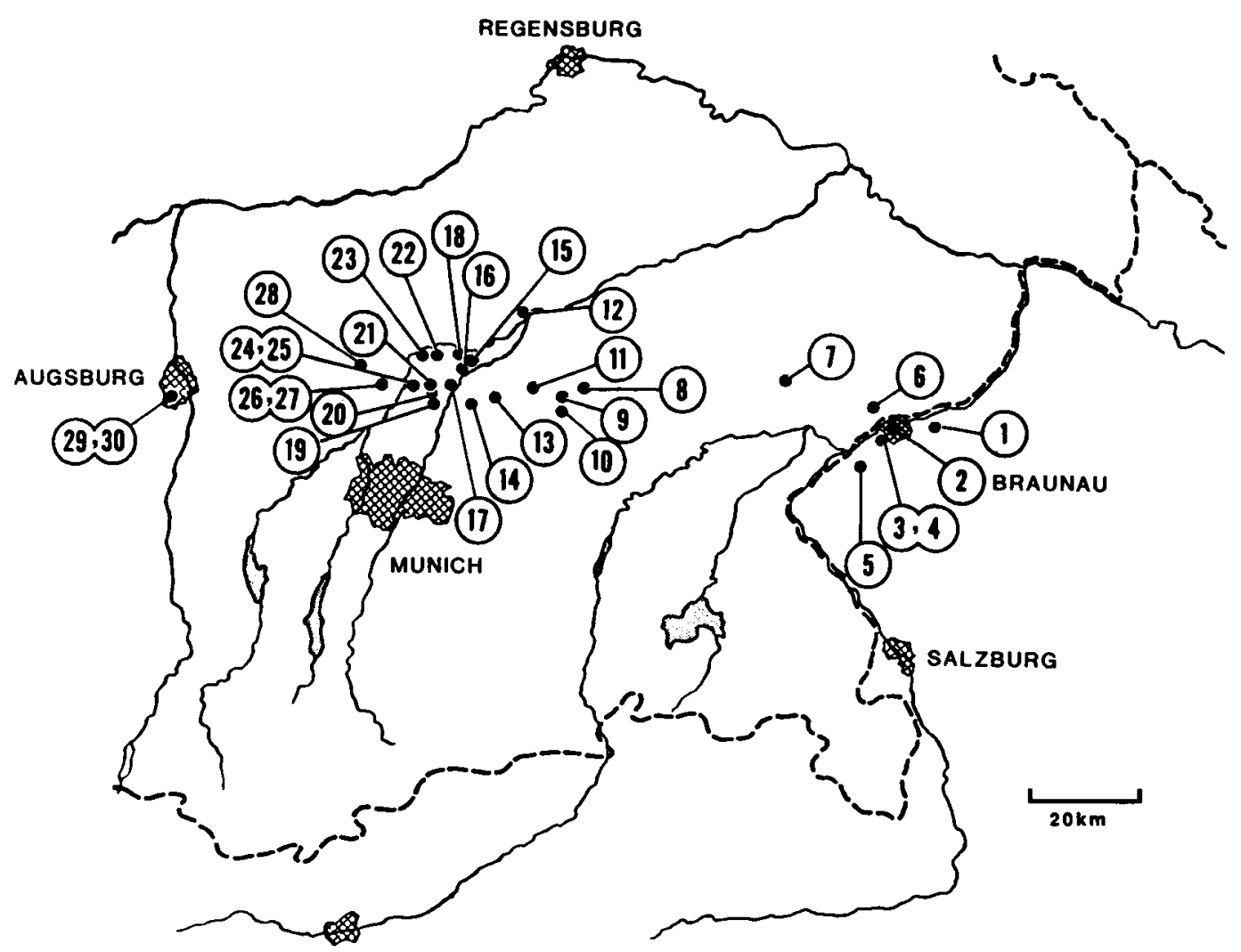

Fig. 1. Collecting localities (1-30) along a $160 \mathrm{~km}$ transect across a hybrid zone between $M$. domesticus and M. musculus in southern Germany and western Austria. Austria: Braunau am Inn Bezirk; Nöfing [Herr Denk]1, Braunau, 26 Laabstrasse [H. Lindhuber]-2, Ranshofen [H. Penia]-3, Ranshofen, 17 Hochstrasse [H. Holfinger]-4, Königsaich-5. F.R.G: Bavaria; Rottal-Inn Kreise; Simbach [H. Huber]-6 $(6 \mathrm{~A}=\mathrm{hay}$ barn, 6B = chicken room, $6 \mathrm{C}=$ furniture room, $6 \mathrm{D}=$ grain attic, $6 \mathrm{E}=$ farm buildings), Mitterskirchen -7 . Erding Kreise, Atting [H. Lechner]-8, Sonnendorf $[$ H. Lech $]-9(9 A=$ feed room, 9B = kitchen $)$, Högersdorf-10, F.-Tittenkofen, 12 Gerichstrasse [H. Wimmer]-11 (11A = grain attic, $11 \mathrm{~B}=$ chicken house). Freising Kreise, $6.5 \mathrm{~km}$ N Dornhaselbach [H. Weber]-12. Erding Kreise, O.-Schwaig [H. Hellinger]-13, Gut Wildschwaige [H. Arnold]-14. Freising Kreise, M.-Rudlfing [H. Heilmayer]-15 (15A = furniture room, 15B = silo), Freising [Bay Wa]-16, Achering, $10 \mathrm{Hwy} 11$ [H. Ziigletrumm]-17, Tüntenhausen [H. Abstreiter]-18, Neufahrn bei Freising, Am Bahndammstrasse [H. Leiss]-19, N'f.-Massenhausen [H. Haagan]-20, N'f.-Giggenhausen, Hauptstrasse, [H. Hecher]-21, Kr.-Thalhausen, Versuchsstation-22, Eberspoint [H. Ostermeyer]-23, Gesselthausen [H. Warta]-24, Gesselthausen, 4 Fichenstrasse [H. Ziigletrumm]-25, Kammerberg, 23 Münchenstrasse [H. Hartl]$26(26 \mathrm{~A}=$ cow barn, 26B = chicken room), Kammerberg, 24 Münchenstrasse [H. Zandt]-27. Dachau Kreise, Ebersbach, 8 Dorfstrasse [H. Beil]-28 (28A = chicken pen, 28B = farm buildings). Augsburg Kreise, Augsburg [Zoologischer Garten, camel stall]-29 [Zoologischer Garten]-30 (30A = quail cage, 30B = birdhouse).

$0.5 \times \mathrm{SSC} / 0.1 \% \mathrm{SDS}$ at room temperature for $15 \mathrm{~min}$, twice at $50^{\circ} \mathrm{C}$ for $30 \mathrm{~min}$, and once at $65^{\circ} \mathrm{C}$ for $30 \mathrm{~min}$.

Analysis of Autoradiographs. - The size of each restriction fragment was ascertained by comparing it to a known sized standard using a customized computer program written for the Apple IIe and a HIPAD digitizer (Houston Instruments).

The species-origin of the $\mathrm{X}$ and $\mathrm{Y}$ loci for each individual was determined by com- paring its hybridization patterns to those obtained from $M$. musculus and $M$. domesticus individuals from outside the hybrid zone (Fig. 2A-C). The species-origin of $\mathrm{X}$ and $Y$ loci for 34 wild-caught males, for which DNA was not available, was determined as follows: Each male was mated to a C57BL/6 or BALB/c female (see Appendix for specific individuals) and one $F_{1}$ male and one $F_{1}$ female were analyzed. The species-origin of the $\mathrm{Y}$ chromosome from the 
TABLE 1. Observed frequencies of $M$. domesticus alleles by locality for seven loci across a zone of contact between $M$. musculus and $M$. domesticus. Numbers in parentheses represent sample sizes for specific loci when different from the sample size listed for a locality.

\begin{tabular}{|c|c|c|c|c|c|c|c|c|c|}
\hline $\begin{array}{c}\text { Local- } \\
\text { ity }\end{array}$ & $\begin{array}{c}\text { Dis- } \\
\text { tance }\end{array}$ & Number ${ }^{b}$ & YB10 & DXW'as68 & DXWas31 & $M p i-1$ & $N p-l$ & $E s-10$ & $E s-I$ \\
\hline $30 \mathrm{~A}$ & 0 & 8 & 1(4) & $1(7)$ & $1(7)$ & 1 & 1 & 1 & 1 \\
\hline $30 \mathrm{~B}$ & 0 & 3 & 1(1) & 1 & 1 & 1 & 1 & i & 1 \\
\hline 29 & 0 & 8 & $1(3)$ & 1 & 1 & i & $i$ & 1 & 1 \\
\hline $28 \mathrm{~A}$ & 37.9 & 1 & 1 & 1 & 1 & 1 & 1 & 1 & 1 \\
\hline $28 \mathrm{~B}$ & 37.9 & 3 & - & 1 & 1 & 1 & 1 & 1 & 1 \\
\hline 27 & 43.7 & 3 & $1(2)$ & 1 & 1 & $i$ & 1 & $i$ & 1 \\
\hline $26 \mathrm{~A}$ & 43.7 & 3 & i(1) & 1 & 1 & $i$ & 1 & $i$ & 1 \\
\hline $26 \mathrm{~B}$ & 43.7 & 1 & - & 1 & 1 & $i$ & 1 & $i$ & 1 \\
\hline 25 & 50.4 & 17 & $1(9)$ & $1(16)$ & 1 & i & 1 & 0.97 & $0.97(15)$ \\
\hline 24 & 50.4 & 38 & $1(19)$ & $1(34)$ & $1(33)$ & $i$ & 1 & 0.74 & $0.95(37)$ \\
\hline 23 & 51.0 & 9 & $1(3)$ & $1(8)$ & $1(8)$ & 0.72 & 0.94 & 0.94 & 0.72 \\
\hline 22 & 55.0 & 1 & 1 & 1 & 0 & 1 & 1 & 1 & 1 \\
\hline 21 & 53.0 & 1 & 0 & $i$ & 1 & $i$ & 1 & $i$ & l \\
\hline 20 & 52.4 & 12 & $0.75(8)$ & $1(11)$ & $1(11)$ & 0.92 & 0.79 & i & $i$ \\
\hline 19 & 54.2 & 68 & $0.89(18)$ & $0.55(57)$ & $0.56(59)$ & 0.55 & 0.81 & 0.23 & $0.63(64)$ \\
\hline 18 & 60.2 & 5 & $0(3)$ & 0.29 & 0.29 & 0.50 & 0.10 & 0 & $0.63(4)$ \\
\hline 17 & 57.6 & 17 & $0.25(4)$ & 0.23 & 0 & 0.09 & 0.24 & 0.71 & 0.09 \\
\hline 16 & 59.8 & 5 & $0(1)$ & 0 & 0 & 0 & 0.50 & 0.50 & 0.70 \\
\hline $15 \mathrm{~A}$ & 65.1 & 22 & $0(11)$ & 0 & 0.29 & 0 & 0.41 & 0.40 & 0.11 \\
\hline $15 \mathrm{~B}$ & 65.1 & 1 & 0 & 0 & 0 & 0 & 0.50 & 0 & 0 \\
\hline 14 & 62.8 & 4 & $O(2)$ & 0 & 0 & 0.25 & 0.50 & 0.25 & 0.25 \\
\hline 13 & 67.9 & 13 & $0(5)$ & $0(12)$ & 0.29 & 0 & 0.15 & 0.27 & 0 \\
\hline 12 & 71.3 & 2 & $0(1)$ & 0 & 0 & 0 & 0.25 & 0 & 0.25 \\
\hline $11 \mathrm{~A}$ & 74.9 & 1 & - & 0 & 0 & 0 & 0.50 & 0 & 0 \\
\hline $11 \mathrm{~B}$ & 74.9 & 1 & - & - & - & 0 & 0 & 0 & 1 \\
\hline 10 & 83.5 & 1 & 0 & 0 & 0 & 0 & 0.5 & 0 & - \\
\hline $9 \mathrm{~A}$ & 82.8 & 21 & $0(5)$ & $0(17)$ & $0(17)$ & $0(20)$ & 0.02 & 0.28 & $0(14)$ \\
\hline $9 \mathrm{~B}$ & 82.8 & 1 & 0 & 0 & 0 & 0 & 0.5 & 0 & 0 \\
\hline 8 & 87.0 & 1 & - & 0 & 0 & 0 & 0 & 0.5 & 0 \\
\hline 7 & 131.9 & 1 & 0 & 0 & 0 & 0 & 0 & 0 & 0 \\
\hline $6 \mathrm{~A}$ & 150.8 & 1 & - & - & - & 0 & 0 & 0 & 1 \\
\hline $6 \mathrm{~B}$ & 150.8 & 4 & $0(2)$ & 0 & 0 & 0 & 0 & 0 & 0.25 \\
\hline $6 \mathrm{C}$ & 150.8 & 2 & $0(1)$ & 0 & 0 & 0 & 0 & 0 & 1 \\
\hline 6D & 150.8 & 2 & $0(1)$ & 0 & 0 & 0 & 0 & 0 & 0 \\
\hline $6 E$ & 150.8 & 7 & $0(2)$ & $0(4)$ & $0(4)$ & $0(6)$ & $0(6)$ & $0(6)$ & $0.42(6)$ \\
\hline 5 & 152.3 & 1 & - & 0 & 0 & 0 & 0 & 0 & - \\
\hline 4 & 153.5 & 4 & $0(2)$ & 0 & 0 & 0 & 0 & 0 & 0.13 \\
\hline 3 & 153.9 & 1 & 0 & 0 & 0 & 0 & 0 & 0 & 0 \\
\hline 2 & 155.7 & 3 & $O(1)$ & $0(2)$ & $0(2)$ & 0 & 0.17 & 0 & $0(1)$ \\
\hline 1 & 158.5 & 5 & $0(3)$ & $0(4)$ & $0(4)$ & 0 & 0 & 0 & $0(2)$ \\
\hline
\end{tabular}

Distance in kilometers from locality 30.
b Number of individual mice sampled per locality.

wild-caught male was deduced by identifying the species-origin of the $\mathrm{Y}$ chromosome of the male progeny. The species-origin of the paternal-linked $\mathrm{X}$ alleles was deduced by first identifying the C57BL/6 or BALB/c X-specific hybridization pattern and eliminating it from the analysis; the remaining $X$-specific allele present being of paternal origin. (One of the two $X$ chromosomes of female progeny is inherited from their wild-caught father and the other (maternal) X chromosome is inherited from their $\mathrm{C} 57 \mathrm{BL} / 6$ or $\mathrm{BALB} / \mathrm{c}$ mother.)
Enzyme Studies. - The species-origin for four autosomal loci was determined using starch gel electrophoresis of plasma, hemolysate, and kidney extracts (Table 1; Appendix) following the methods of Sage (1978). These loci included mannose phosphate isomerase-1 ( $\mathrm{Mpi}-\mathrm{l})$ (Chromosome 9), esterase-1 (Es-1) (Chromosome 8), and esterase-10 (Es-10) and nucleoside phosphorylase-1 ( $\mathrm{Np}-1)$ (Chromosome 14). Previous studies have demonstrated fixed allelic differences between $M$. musculus and $M$. domesticus at these four loci. The Es-10 

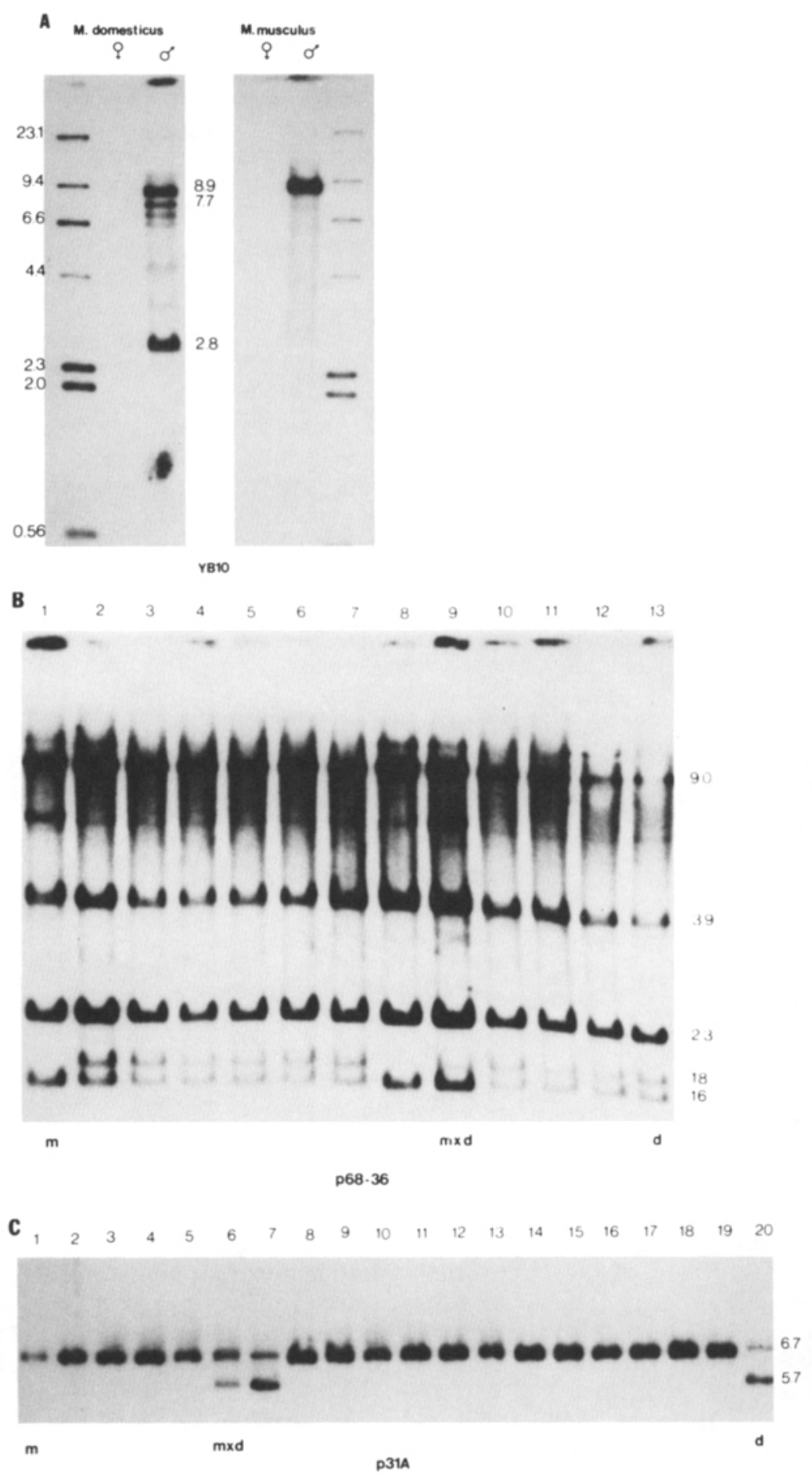

Fig. 2. Autoradiographs of enzyme restricted genomic DNA hybridized with sex chromosome-specific DNA probes. A. Genomic DNA from male and female $M$. domesticus and $M$. musculus mice collected from outside the hybrid zone. DNA was digested with PvuII and hybridized with the Y-specific probe $Y B 10$ (Y). No hybridization occurs to female DNA. A doublet $(8.9 \mathrm{~kb})$ is shared by $M$. domesticus and $M$. musculus males and two $P v u I I$ fragments $(7.7 \mathrm{~kb}$ and $2.8 \mathrm{~kb}$ ) are present in $M$. domesticus and absent in $M$. musculus males. Other 
and $N p-1$ loci are located only $10 \mathrm{cM}$ apart on Chromosome 14 (Womack et al., 1977) and thus do not represent an independent test of movement.

Statistical Analyses. - A standard fixed effects logistic regression (FELR) analysis (Hosmer and Lemeshow, 1989) was performed to describe cline shape for the seven genetic loci. In addition, the FELR analysis was performed on a subset of data for two loci $(E s-1$ and $N p-1)$ in which outliers appeared to be present. Specifically, locality 2 was omitted from the $N p-1$ analysis, and localities $4,6 \mathrm{~A}, 6 \mathrm{~B}, 6 \mathrm{C}$, and $6 \mathrm{E}$ were omitted from the Es- 1 analysis. FELR is a standard statistical tool used to model the effects of one or more independent variables on a dichotomous dependent variable. In the present study, the dependent variable $Y_{i}$ is 1 if a $M$. domesticus allele is present at a given locus in animal $i$ and 0 otherwise. The independent variable (or covariate) $x$ is the distance from the westernmost locality (locality 30) sampled. Under the fixed effects logistic regression model the random variables $y_{i}$ are independent of each other, and

$$
\begin{aligned}
& P\left\{Y_{i}=1 \mid x\right\} \\
& \quad=\frac{1}{1+\exp [2.7746(x-m) / c]}
\end{aligned}
$$

where $m$ is the cline midpoint and $|c|$ is the cline width. Cline midpoint is defined as the distance from the edge of the hybrid zone (locality 30 ) to the place where the expected frequency of the $M$. domesticus al- lele is 0.5 . Cline width is the distance over which the expected frequency of the $M$. domesticus allele changes from 0.8 to 0.2 (after Endler, 1977).

In addition to the FELR analysis, we fit two random effects logistic regression (RELR) models, the beta-binomial model (Crowder, 1978) and the logistic normal model (Anderson and Aitkin, 1985). These models are less well known than the standard FELR model and are currently an active area of statistical investigation. A summary of current research can be found in McCullagh and Nelder (1989; pp. 450-451) and in Zeger and Rezaul (1991).

The principal advantage of the RELR models is that they allow one to account for variation in the probability that an individual will have a species-specific allele (in this case, the $M$. domesticus allele) at a collecting site. For example, mice at different collecting sites that are equally distant from the westernmost locality may have markedly different probabilities of carrying a $M$. domesticus allele. If the collecting sites can be distinguished by means of additional covariates, these could be incorporated into a FELR model. If no suitable covariates are found and differences between collecting sites are large enough to produce significant lack of fit in the FELR model, a random effects logistic regression model is a logical alternative. Under the logistic-normal model the probability that an individual $i$ at collecting site $j$ will display a $M$. domesticus allele is given by

\footnotetext{
fragments present in $\boldsymbol{M}$. domesticus males are not species-specific. B. Genomic DNA from male and female mice collected from the hybrid zone. Outside lanes are control samples of genomic DNAs from male $M$. domesticus (d) and $M$. musculus (m) mice collected from outside the hybrid zone. DNA was digested with $P v u I I$ and hybridized with the X-specific probe p68-36 $(X I)$. Four $P v u I I$ fragments $(9.0 \mathrm{~kb}, 3.9 \mathrm{~kb}, 2.3 \mathrm{~kb}$, and 1.6 kb) are shared between $M$. musculus and $M$. domesticus and one $P v u I I$ fragment $(1.8 \mathrm{~kb})$ differentiates $M$. domesticus from $M$. musculus. Lanes 3-7 and 10-12 contain DNA from males with the $M$. domesticus X-specific pattern for the single $\mathrm{X}$ chromosome and lane 2 contains female DNA with the $M$. domesticus X-specific pattern for both $\mathrm{X}$ chromosomes. Lane 8 contains DNA from a male with the $M$. musculus pattern for the single $\mathrm{X}$ chromosome. Lane 9 contains DNA from a female with the $M$. domesticus pattern for one X chromosome and the $M$. musculus pattern for the other X chromosome. C. Genomic DNA from male and female mice collected from the hybrid zone between $M$. domesticus (d) and $M$. musculus $(\mathrm{m})$. Outside lanes are control samples as described in B. DNA was digested with SstI and hybridized with the X-specific probe p31A (X2). A $6.7 \mathrm{~kb} S s t \mathrm{I}$ fragment is shared between $M$. domesticus and $M$. musculus and a $5.7 \mathrm{~kb} S s t$ fragment differentiates $M$. domesticus from $M$. musculus. Lanes 2-5 and 8-19 contain DNA from females with the $M$. musculus pattern for both $\mathrm{X}$ chromosomes. Lane 7 contains DNA from a female with the $M$. domesticus pattern for both $\mathrm{X}$ chromosomes and lane 6 contains DNA from a female with the $M$. domesticus pattern for one X chromosome and the $M$. musculus pattern for the second $\mathrm{X}$ chromosome.
}

$\longleftarrow$ 


$$
\begin{aligned}
P & \left\{Y_{i j}=1 / x\right\} \\
& =\frac{\exp \left[2.7746(x-m) / c+u_{j}\right]}{\left\{1+\exp \left[2.7746(x-m) / c+u_{j}\right]\right\}}
\end{aligned}
$$

where $u_{j}$ is an unobserved normally distributed random variable with mean zero and standard deviation $\sigma$. Note that $u_{j}$ has the effect of introducing a correlation between the responses of individuals at the same collecting site (a response being equivalent to the presence of a $M$. domesticus allele). Under the beta-binomial model the number of individuals at each collecting site that have a $M$. domesticus allele is a binomial random variable with mean $k_{j} P_{j}$, where $k_{j}$ is the total number of individuals at the site and $P_{j}$ is a beta random variable with a mean $\mu_{j}$ given by the right-hand side of equation (1) and variance $\mu_{\mathrm{j}}\left(1-\mu_{\mathrm{j}}\right) \mathrm{F}_{\mathrm{ST}} \cdot\left(\mathrm{F}_{\mathrm{ST}}=\sigma / 1+\sigma\right.$, where $\sigma$ is the shape parameter given as output by EGRET.)

All logistic regressions were fit using the commercially available EGRET package (EGRET Statistical Packages, Statistics and Epidemiology Research Corporation, Seattle, WA USA). (An alternative approach to fitting these models using the Royal Statistical Society's package GLIM can be found in Williams, 1982.) After fitting the data, the models were reparameterized as in equations (1) and (2) so that $P\{Y=1\}$ would be a function of the cline midpoint and width. In the case of the RELR models, $P\{Y$ $=1\}$ is also a function of the random effects standard deviation. Standard errors for the transformed variables were calculated from the output of EGRET by means of equation 6.62 of Kish (1965).

\section{RESULTS}

Cline Analysis. - Genotypes for Y chromosomal, $\mathrm{X}$ chromosomal, and autosomal loci were tabulated for each individual (Appendix). Based on these results, individuals were classified as $M$. domesticus, as $M$. musculus or as hybrids. Among those classified as hybrids, only a single putative $F_{1}$ hybrid individual (MVZ 172487) was identified. Examples of hybrid individuals included males with a recombinant $X$ chromosome and mismatched $X$ and $Y$ chromosomes or females with either mismatched or recombinant $\mathrm{X}$ chromosomes (Appendix). In ad- dition, many individuals had a recombinant Chromosome 14 , as determined by genotypic data for $E s-10$ and $N p-1$ (Appendix).

Observed frequencies of the $M$. domesticus alleles for $Y B 10, X 1, X 2, M p i-1, N p$ $1, E s-10$, and $E s-1$ were determined for each of 40 collecting sites along the transect (Table 1, Fig. 3).

Statistical Analyses. - A goodness of fit analysis was performed on all three logistic regression models for nine data sets. These included the seven loci with all localities included, $N p-1$ with locality 2 omitted and $E s-1$ with localities $4,6 \mathrm{~A}, 6 \mathrm{~B}, 6 \mathrm{C}$, and $6 \mathrm{E}$ omitted (Table 2). The deviance presented in Table 2 is a likelihood ratio statistic used in comparing the saturated model, i.e., the model in which the probability of the $M$. domesticus allele at each collecting site is estimated separately with each of the three logistic models. Under the null hypothesis that one of our models fits the data, the deviance should be distributed approximately as a chi-squared statistic on $m$ degrees of freedom, where $m$ is the number of collecting sites - number of parameters. The number of parameters is two for the FELR model and three for the RELR model. The results of the analysis indicate that the FELR model does not fit the data with the exception of $Y B 10$ and $X 1$. In addition $N p-1$ and $E s-1$ cannot be fit to any of the models without dropping outliers (i.e., samples from locality 2 for $N p i-1$, and samples from localities $4,6 \mathrm{~A}, 6 \mathrm{~B}, 6 \mathrm{C}$, and $6 \mathrm{E}$ for $E s-1$ ). When these samples are omitted, the data is fit well by both the logistic normal and beta binomial RELR models. Es-10, $M p i-1$, and $X 2$ are also fit equally well by the two RELR models. Although no clear choice can be made between the beta-binomial and logistic normal models based on the goodnessof-fit statistics (Table 2), we observed pronounced multi-modality in the likelihood functions for some of the logistic normal fits that leads us to doubt the accuracy of the standard errors associated with the logisticnormal model when applied to these data. In addition, the similarity between the coefficients of the beta-binomial and the FELR models in cases where the FELR fit, leads us to rely on the beta-binomial coefficients. An additional advantage of the beta-binomial model over the logistic normal model 

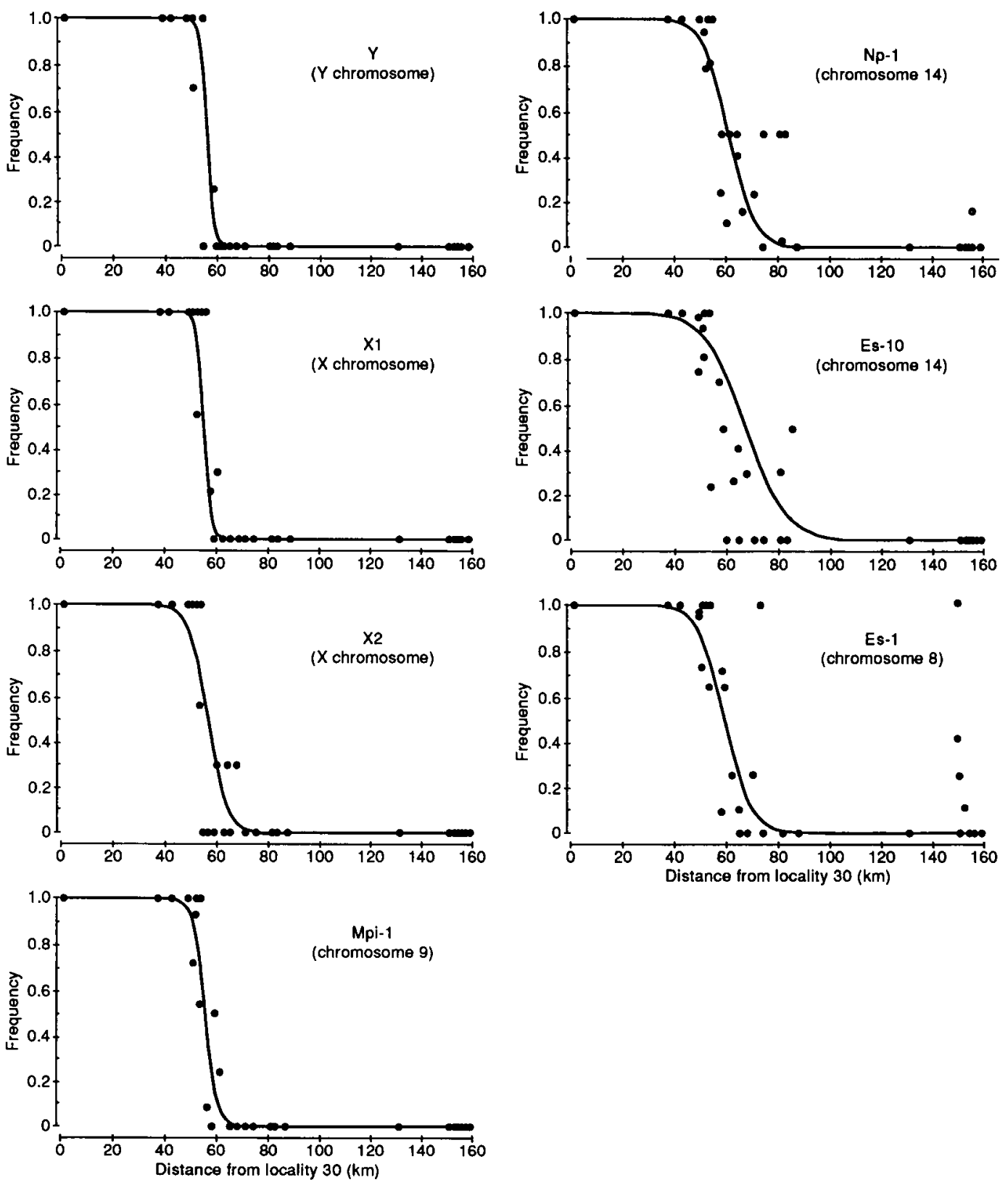

Fig. 3. Observed and expected frequencies of $M$. domesticus alleles at seven genetic loci across the hybrid zone between $M$. domesticus and $M$. musculus. Observed frequencies (closed circles) were determined for each of 40 collecting sites. Each collecting site is identified by distance in kilometers from locality 30 . Collecting sites of equal distance from locality 30 with identical observed frequencies are represented by a single cirlce. Expected frequencies (solid lines) were determined using the beta binomial logistic regression model with localities 2 , and $4,6 \mathrm{~A}, 6 \mathrm{~B}, 6 \mathrm{C}$, and $6 \mathrm{E}$ omitted for loci $N p-I$ and $E s-1$, respectively.

is that $\mathrm{F}_{\mathrm{ST}}$ is a parameter in the former but not the latter. Estimates of the cline midpoint, cline width and $F_{S T}$ based on the betabinomial model are given for each locus in Table 3. A graphical representation of cline shape is given for each locus in Figure 3.

\section{Discussion}

Cline Analysis. - The pattern of movement for the sex chromosomal alleles (in particular $Y B 10$ and $X 1$ ) indicate that $\mathrm{X}$ and $\mathrm{Y}$-linked alleles move to a more limited 
TABLE 2. A goodness of fit analysis for three logistic regression models applied to each of the seven loci.

\begin{tabular}{|c|c|c|c|}
\hline & $\begin{array}{l}\text { Fixed } \\
\text { effects }\end{array}$ & $\begin{array}{l}\text { Logistic } \\
\text { normal }\end{array}$ & $\begin{array}{c}\text { Beta } \\
\text { binomial }\end{array}$ \\
\hline \multicolumn{4}{|l|}{$Y$} \\
\hline Deviance & 10.801 & 10.652 & 10.515 \\
\hline$d f$ & 31.000 & 30.000 & 30.000 \\
\hline Signif. & 1.000 & 1.000 & 1.000 \\
\hline \multicolumn{4}{|l|}{$X I$} \\
\hline Deviance & 25.566 & 16.390 & 14.222 \\
\hline$d f$ & 36.000 & 35.000 & 35.000 \\
\hline Signif. & 0.902 & 0.997 & 0.999 \\
\hline \multicolumn{4}{|l|}{$X 2$} \\
\hline Deviance & 112.73 & 37.691 & 34.839 \\
\hline$d f$ & 36.000 & 35.000 & 35.000 \\
\hline Signif. & 0.000 & 0.347 & 0.476 \\
\hline \multicolumn{4}{|l|}{$M p i-1$} \\
\hline Deviance & 57.322 & 28.055 & 28.440 \\
\hline$d f$ & 38.000 & 37.000 & 37.000 \\
\hline Signif. & 0.023 & 0.855 & 0.843 \\
\hline \multicolumn{4}{|l|}{$N p-1$} \\
\hline Deviance & 113.000 & 62.961 & 62.351 \\
\hline$d f$ & 38.000 & 37.000 & 37.000 \\
\hline Signif. & 0.000 & 0.005 & 0.006 \\
\hline \multicolumn{4}{|l|}{$N p-I^{\mathrm{a}}$} \\
\hline Deviance & 83.689 & 48.621 & 47.893 \\
\hline$d f$ & 37.000 & 36.000 & 36.000 \\
\hline Signif. & 0.000 & 0.078 & 0.089 \\
\hline \multicolumn{4}{|l|}{$E s-10$} \\
\hline Deviance & 177.85 & 51.119 & 52.636 \\
\hline$d f$ & 38.000 & 37.000 & 37.000 \\
\hline Signif. & 0.000 & 0.061 & 0.046 \\
\hline \multicolumn{4}{|l|}{$E_{s-1}$} \\
\hline Deviance & 296.31 & 92.629 & 92.900 \\
\hline$d f$ & 36.000 & 35.000 & 35.000 \\
\hline Signif. & 0.000 & 0.000 & 0.000 \\
\hline \multicolumn{4}{|l|}{$E s-I^{\mathrm{b}}$} \\
\hline Deviance & 81.534 & 45.510 & 45.916 \\
\hline$d f$ & 31.000 & 30.000 & 30.000 \\
\hline Signif. & 0.000 & 0.004 & 0.032 \\
\hline
\end{tabular}

a Locality 2 deleted from the analysis.

${ }^{b}$ Localities $4,6 \mathrm{~A}, 6 \mathrm{~B}, 6 \mathrm{C}$, and $6 \mathrm{D}$ deleted from the analysis.

extent across the hybrid zone compared to autosomal alleles for $E s-10, E s-1$, and $N p-1$ (Table 3, Fig. 3). The cline shape for both $N p-1$ and $E s-1$ were estimated after removing outlier samples from localities 2 , and 4 , $6 \mathrm{~A}, 6 \mathrm{~B}, 6 \mathrm{C}$, and $6 \mathrm{E}$, respectively. The presence of $M$. domesticus alleles in these eastern-most localities may represent either isolated pockets of $M$. domesticus alleles in $M$. musculus territory or a continuous eastern flow of $M$. domesticus alleles across the hybrid zone. This cannot be ascertained with- out additional sampling between localities 7 and 8, a region spanning approximately $45 \mathrm{~km}$. If the presence of $M$. domesticus alleles at localities $2,4,6 \mathrm{~A}, 6 \mathrm{~B}, 6 \mathrm{C}$, and $6 \mathrm{E}$ represents a continuous eastern flow of $M$. domesticus alleles across the hybrid zone, then the cline width for $E s-1$ and $N p i-1$ is grossly underestimated. Regardless, the presence of $M$. domesticus alleles for autosomal loci and the absence of $M$. domesticus alleles for sex chromosomal loci at these same localities are significant findings because they suggest that, while $M$. domesticus alleles for some autosomal loci are neutral on a predominantly $M$. musculus genetic background, $M$. domesticus alleles for Xand $\mathrm{Y}$-linked loci are selected against on a predominantly $M$. musculus genetic background.

$Y$ Chromosome-Derived Locus. - Because all $\mathrm{Y}$ chromosome-derived loci located outside the pseudoautosomal region (i.e., the region of the $\mathrm{X}$ and $\mathrm{Y}$ chromosomes that recombines during male meiosis) are genetically linked any species-specific $Y$-linked allele is diagnostic for the species-origin of virtually the entire $Y$ chromosome. Evidence for the restricted flow of $\mathrm{Y}$ chromosome-specific alleles along two other Mus domesticus and Mus musculus hybrid zone transects, one in Denmark and one in Bulgaria, was documented by Vanlerberghe et al. $(1986,1988 b)$. These authors suggest that the limited movement of the Y chromosome may result from the disruption of a co-adapted gene complex involving the interaction of a $\mathrm{Y}$ chromosome locus or loci from one species and an autosomal locus or loci from the other species.

Indirect evidence for this kind of phenomenon has been obtained by Eicher and Washburn (1986) and Eicher (1988), who showed that the normal developmental pathway leading to male primary sex determination (testis development) is disrupted when a Y chromosome of Mus domesticus origin is transferred onto the genome of the C57BL/6J inbred mouse strain that normally contains a $M$. musculus Y chromosome (Tucker et al., 1992). Eicher and Washburn (1986) and Eicher (1988) hypothesized that this disruption, resulting in the formation of ovotestes or ovaries in place of testes, is caused by species-specific allelic 
TABLE 3. Estimates of cline width, cline midpoint, and $F_{S T}$ for seven genetic loci using the beta binomial RELR model.

\begin{tabular}{lcccc}
\hline \hline Locus & $\begin{array}{c}\text { Chromosome } \\
\text { location }\end{array}$ & $\begin{array}{c}\text { Cline width } \\
\text { km }\end{array}$ & $\begin{array}{c}\text { Cline midpoint }^{\mathrm{a}} \\
\text { km from locality } 30\end{array}$ & Fst $^{\mathrm{b}}$ \\
\hline $\mathrm{Y}$ & $\mathrm{Y}$ & $4.0(1.15)$ & $55.9(0.86)$ & $0.05(0.111)$ \\
$X 1^{c}$ & $\mathrm{X}$ & $3.9(0.98)$ & $56.5(0.95)$ & $0.19(0.144)$ \\
$X 2^{d}$ & $\mathrm{X}$ & $9.9(3.25)$ & $57.8(1.81)$ & $0.55(0.168)$ \\
$M p i-1$ & 9 & $6.4(1.56)$ & $56.4(1.02)$ & $0.24(0.121)$ \\
$N p-I^{e}$ & 14 & $21.2(4.65)$ & $64.6(2.41)$ & $0.21(0.082)$ \\
$E s-10$ & 14 & $20.9(2.46)$ & $68.1(1.34)$ & $0.69(0.064)$ \\
$E s-I^{f}$ & 8 & $14.1(3.41)$ & $59.8(1.63)$ & $0.26(0.103)$ \\
\hline
\end{tabular}

a The standard error for cline width and midpoint is given in parentheses.

b Inferences based on standard errors for the $F_{S T}$ values do nol agree with inferences based on the deviance from Table 2 and therefore may be unreliable.

c $X 1=D X W a \operatorname{los} 8$

d $X 2=D X W a{ }^{3} 31$.

e Locality 2 deleted.

Localities $4,6 \mathrm{~A}, 6 \mathrm{~B}, 6 \mathrm{C}$, and $6 \mathrm{E}$ deleted

variation at the $\mathrm{Y}$ chromosome testis-determining ( $T d y)$ locus and autosomal loci involved in testis determination, and that the mismatching of species-specific $T d y$ alleles and autosomal alleles in backcross generations results in the formation of sex-reversed (XY females) and hermaphroditic $X Y$ individuals. Whether this type of $Y$ chromosome-autosome interaction occurs in the hybrid zone between $M$. domesticus and $M$. musculus remains to be tested. Y chromosome-autosome imbalance resulting in asymmetrical male sterility also has been documented in Drosophila (Vigneault and Zouros, 1986).

Because both the $\mathrm{Y}$ chromosome (excepting the pseudoautosomal region as noted above) and mitochondrial DNA (mtDNA) are clonally and uniparentally inherited, one might predict that both are subjected equally to such population phenomena as founder events and bottlenecks. For example, populations have been found in Denmark and in Austria where $M$. domesticus mtDNA is fixed in mice with a predominantly $M$. musculus nuclear genome (Ferris et al., 1983; Gyllensten and Wilson, 1987; Sage and Wilson, unpubl. obs.). However, isolated populations in which the $M$. domesticus $\mathrm{Y}$ chromosome is fixed in an otherwise predominantly $M$. musculus nuclear genome, or vice versa, were not found in this study or in studies conducted in Denmark or Bulgaria (Vanlerberghe et al., 1986, 1988b). One explanation for this difference is that mtDNA is not under the same selective constraints as are $\mathrm{Y}$-linked loci, i.e., mtDNA is selectively neutral in hybrid individuals (Gyllensten et al., 1985).

The limited flow of the paternally-inherited $Y$ chromosome also may be indicative of limited successful migrations of males relative to females from both species across the hybrid zone. If male mice from either species do not migrate as frequently as female mice, one would predict limited movement of a paternally-inherited character (i.e., the $Y$ chromosome). Sex differences in dispersal have been reported for these species in two separate studies. However, in one study females dispersed to a greater extent than males, whereas in the other study males dispersed to a greater extent than females (reviewed in Sage, 1981).

$X$ Chromosome-Derived Loci. - In addition to the limited flow of $\mathrm{X}$ chromosomal loci across the hybrid zone between $M$. domesticus and $M$. musculus reported here, restricted flow of morphologically distinct $\mathrm{X}$ chromosomes has been reported in hybrid zones between two races of the grasshopper species Caledia captiva (Moran, 1979; Shaw and Wilkinson, 1980) and between two races of the grasshopper species Chorthippus parallelus (Hewitt et al., 1988). In addition, the lack of the flow of X-linked alleles has been reported in a hybrid zone between two races of the swallowtail butterfly Papilio glaucus (Hagen, 1990), and between two species of water strider Limnoporus dissortis and $L$. notabilis (Sperling and Spence, 1991). These reports are relevant to hypotheses proposed to explain the 
genetic basis of Haldane's rule of heterogametic inviability or sterility (Haldane, 1922). All of these hypotheses suggest that genes on the $\mathrm{X}$ chromosome strongly contribute to postzygotic reproductive isolation (Haldane, 1922; Dobzhansky, 1937; Coyne, 1985; Coyne and Orr, 1989). Most recently, Coyne and Orr (1989) have proposed a hypothesis in which the large effect of the $X$ chromosome on postzygotic reproductive isolation results from a more rapid divergence rate for $\mathrm{X}$ chromosomal versus autosomal loci in related species, and consequently a more rapid accumulation of alleles on the $\mathrm{X}$ chromosome that ultimately cause sterility or inviability when placed on a hybrid background.

We hypothesize that limited movement of X-specific alleles in both male and female mice across the hybrid zone results from disruption of a co-adapted gene complex involving the "mismatching" of speciesspecific alleles at X-derived and autosomalderived loci. Presumably, this disruption occurs in backcross generations as Vanlerberghe et al. (1986) have demonstrated that reciprocal crosses between $M$. domesticus and $M$. musculus from Bulgaria produce viable and fertile $F_{1}$ male and female offspring. The slight difference in movement between the two $\mathrm{X}$-derived loci $X 1$ and $X 2$ studied here suggest that different regions of the $\mathrm{X}$ chromosome carry loci that interact in different ways with other (autosomal) loci. The more limited movement of $X 1$ alleles compared to $X 2$ alleles suggest that "mismatched" loci in the proximal region of the $\mathrm{X}$ may be under greater selection than " $\mathrm{mis}$ matched" loci in the distal region of the $X$. We predict that alleles of autosomal loci interacting with $\mathrm{X}$ chromosomal loci also will move to a limited extent.

Autosomal Locus Mpi-1.-The limited movement of $M p i-1$ alleles in this study (Table 3, Fig. 3) contrasts with the broad movement of $M p i-1$ alleles across the Bulgarian transect (Vanlerberghe et al., 1986). This difference is not readily explained but can serve as a caveat that loci may behave differently at different interfaces along the $M$. domesticus-M. musculus hybrid zone. It is possible that intra-species allelic variation at specific loci occurs along the hybrid zone, and polymorphic loci may interact with allelic variants of other loci in profoundly different ways across the hybrid zone.

Conclusion. - These observations, in addition to documentation of the virtual absence of $F_{1}$ hybrids, suggest that differential movement of genes occurs across a hybrid zone characterized by the extensive mixing of $M$. domesticus and $M$. musculus genomes over a limited geographic range. Locus-bylocus analysis using RELR analysis has provided a means of statistically comparing and contrasting the behavior of individual genetic loci or closely linked loci across hybrid zones. This analytical method provides insight into the nature of genetic differences across a hybrid zone between two species and, by extrapolation, may shed light on the kinds of genetic differences that accompany or give rise to species divergence. The limited movement of both $\mathrm{X}$ and $\mathrm{Y}$ chromosome-derived loci across the hybrid zone between $M$. domesticus and $M$. musculus suggests that $\mathrm{X}$ - and $\mathrm{Y}$-linked loci interact with autosomal loci in some critical speciesspecific way. One could hypothesize that the fixation of allelic variants at X-and Y-linked loci in allopatric populations of the ancestor common to $M$. domesticus and $M$. musculus has subsequently contributed to hybrid breakdown in parapatric populations of these two species. Whether allelic variation at sex chromosomal loci contributes in a disproportionate way to hybrid breakdown between $M$. domesticus and $M$. musculus compared to autosomal loci, as hypothesized by Coyne and Orr (1989), requires a more extensive comparison of movement among additional autosomal loci across the hybrid zone.

\section{ACKNOWLEDGMENTS}

We gratefully acknowledge I. Butler, $\mathrm{K}$. Damme, J. Klein, R. Kraft, F. Pirchner, F. Seidl, and $\mathrm{H}$. Tichy for help in collecting and transporting mice. We thank T. Bishop for originally advising us on the logistic regression analysis. We thank N. Barton, J. Coyne, R. Hagen, D. Hale, J. Nadeau, and E. Prager for reviewing an earlier version of the manuscript. We also thank $\mathrm{C}$. Disteche, The University of Washington, for the gift of the X-specific probes. The field work and enzyme analyses were supported by a $\mathrm{Na}$ - 
tional Science Foundation grant to A. C. Wilson. The sex chromosome analyses were supported by National Institutes of Health grants HD07065 to The Jackson Laboratory and GM20919 to E. M. Eicher.

\section{Literature Cited}

Anderson, D. A., ANd M. Aitkin. 1985. Variance components models with binary response: Interviewer variability. J. R. Stat. Soc. Ser. B 47:203210.

. 1985. Analysis of hybrid zones. Annu. Rev. Ecol. Syst. 16:113-148.

COYNE, J. A. 1985. The genetic basis of Haldane's rule. Nature 314:736-738.

CoYne, J. A., AND H. A. ORR. 1989. Two rules of speciation, pp. 180-207. In D. Otte and J. A. Endler (eds.), Speciation and its Consequences. Sinauer Assoc. Inc., Sunderland, MA USA.

Crowder, M. J. 1986. Beta-binomial anova for proportions. Appl. Stat. 27:34-37.

Disteche, C. M., L. M. Kunkel, A. Lojewski, S. H. Orkin, M. Eisenhard, E. Sahar, B. Travis, and S. A. LATT. 1982. Isolation of mouse X-chromosome specific DNA from an X-enriched lambda phage library derived from flow sorted chromosomes. Cytometry 2:282-286.

Disteche, C. M., G. K. McConnell, S. G. Grant, D. A. Stephenson, V. M. Chapman, S. Gandy, and D. A. Adler. 1989. Comparison of the physical and recombinational maps of the mouse $X$ chromosome. Genomics 5:177-184.

Disteche, C. M., U. Tantravahi, S. Gandy, M. EISENHARD, D. Adler, AND L. M. Kunkel. 1985. Isolation and characterization of two repetitive DNA fragments located near the centromere of the mouse X chromosome. Cytogenet. Cell Genet. 39:262-268.

Dobzhansky, T. H. 1937. Further data on Drosophila miranda and its hybrids with Drosophila pseudoobscura. J. Hered. 34:135-151.

EICHER, E. M. 1988. Autosomal genes involved in mammalian primary sex determination. Phil. Trans. R. Soc. Lond. B. 322:109-118.

EICHER, E. M., AND L. L. WashbuRn. 1986. Genetic control of primary sex determination in mice. Ann. Rev. Genet. 20:327-360.

Eicher, E. M., K. W. Hutchison, S. J. Phillips, P. K. TUCKER, AND B. K. LEE. 1989. A repeated segment on the mouse $Y$ chromosome is composed of retroviral-related, $Y$-enriched and $Y$-specific sequences. Genetics 122:181-192.

ENDLER, J. 1977. Geographic Variation, Speciation and Clines. Princeton Univ. Press, Princeton, NJ USA.

Feinberg, A. P., AND B. Vogelstein. 1983. A technique for radiolabeling DNA restriction endonuclease fragments to high specific activity. Anal. Biochem. 132:6-13.

1984. A technique for radiolabeling DNA restriction endonuclease fragments to high specific activity. Anal. Biochem. 137:266-267.

Ferris, S. D., R. D. SAge, C.-M. Huang, J. T. Nielsen, U. Ritte, AND A. C. Wilson. 1983. Flow of mi- tochondrial DNA across a species boundary. Proc. Natl. Acad. Sci. USA 80:2290-2294.

Gyllensten, U., AND A. C. Wilson. 1987. Interspecific mitochondrial DNA transfer and the colonization of Scandinavia by mice. Genet. Res., Camb. 49:25-29.

Gyllensten, U., D. Wharton, and A. C. Wilson. 1985. Maternal inheritance of mitochondrial DNA during backcrossing of two species of mice. J. Hered. 76:321-324.

Hagen, R. H. 1990. Population structure and host use in hybridizing subspecies of Papilio glaucus (Lepidoptera: Papilionidae). Evolution 44:19141930.

Haldane, J. B. S. 1922. Sex ratio and unisexual sterility in animal hybrids. J. Genet. 12:101-109.

HewitT, G. M. 1988. Hybrid zones-Natural laboratories for evolutionary studies. Trends Ecol. Evol. 3:158-167.

- 1989. The subdivision of species by hybrid zones, pp. 85-110. In D. Otte and J. A. Endler (eds.), Speciation and its Consequences. Sinauer Assoc. Inc., Sunderland, MA USA.

Hewitt, G. M., M. J. Gosalvez, C. Lopez-Fernandez, M. G. Ritchie, W. Nichols, and R. K. Butlin. 1988. Differences in the nucleolar organisers, on sex chromosomes and Haldane's Rule in a hybrid zone, pp. 109-1 19. In P. E. Brandham (ed.), Kew Chromosome Conference III. HMSO, London, UK.

Hosmer, D. W., AND S. Lemeshow. 1989. Applied Logistic Regression. Wiley and Sons, N.Y., USA.

Hunt, W. G., ANd R. K. Selander. 1973. Biochemical genetics of hybridisation in European house mice. Heredity 31:11-33.

Jenkins, N. A., N. G. Copeland, B. A. TAylor, AND B. K. LEE. 1982. Organization, distribution and stability of endogenous ecotropic murine leukemia virus DNA sequences in chromosomes of $\mathrm{MuS}$ musculus. J. Virol. 43:26-36.

KisH, L. 1965. Survey Sampling. John Wiley and Sons, N.Y., USA.

Maniatis, T., E. F. Fritsch, and J. Sambrook. 1982. Molecular Cloning, A Laboratory Manual. Cold Spring Harbor, NY USA.

McCullagh, P., ANd J. A. Nelder. 1989. Generalized Linear Models. Chapman and Hall, N.Y., USA.

MORAN, C. 1979. The structure of the hybrid zone in Caledia captiva. Heredity 42:13-32.

OrR, H. A. 1987. Genetics of male and female sterility in hybrids of Drosophila pseudoobscura and D. persimilis. Genetics 116:555-563.

REED, K. C., AND D. A. MANN. 1985. Rapid transfer of DNA from agarose gels to nylon membranes. Nucleic Acids Res. 13:7207-7221.

SAGE, R. D. 1978. Genetic heterogeneity of Spanish house mice (Mus musculus complex), pp. 519-553. In H. C. Morse III (ed.), Origins of Inbred Mice. Academic Press, N.Y., USA.

- 1981. Wild mice, pp. 40-90. In H. L. Foster, J. D. Small, and J. G. Fox (eds.), The Mouse in Biomedical Research, Vol. 1. Academic Press, N.Y., USA.

Sage, R. D., J. B. Whitney III, And A. C. WILson. 1986a. Genetic analysis of a hybrid zone between domesticus and musculus mice (Mus musculus 
complex): Hemoglobin polymorphisms. Curr. Top. Microb. Immunol. 127:75-85.

Sage, R. D., D. Heyneman, K.-C. Lim, and A. C. WILSON. $1986 b$. Wormy mice in a hybrid zone. Nature 324:60-63.

Shaw, D. D., AND P. WILkINSON. 1980. Chromosomal differentiation, hybrid breakdown and the maintenance of a hybrid zone in Caledia. Chromosoma 80:1-31.

SPERling, F. A. H., AND J. R. SPENCE. 1991. Structure of an asymmetric hybrid zone between two water strider species (Hemiptera: Gerridae: Limnoporus). Evolution 45:1370-1383.

Tucker, P. K., B. K. LeE, AND E. M. Eicher. 1989. $\mathrm{Y}$ chromosome evolution in the subgenus Mus (genus Mus). Genetics 122:169-180.

VANLeRberghe, F., B. Dod, P. Boursot, M. Bellis, AND F. BONHOMME. 1986. Absence of Y-chromosome introgression across the hybrid zone between Mus muculus domesticus and Mus musculus musculus. Genet. Res., Camb. 48:191-197.

VANLeRberghe, F., P. Boursot, J. T. Nielsen, AND F. BONHOMME. 1988a. A steep cline for mitochondrial DNA in Danish mice. Genet. Res., Camb. 52: 185-193.
Vanlerberghe, F., P. Boursot, J. Catalan, S. Gerasimov, F. BONHOMME, B. A. BOTEV, L. AND L. THALER. 1988b. Analyse genetique de la zone d'hybridation entre les deux sous-especes de souris Mus musculus domesticus et Mus musculus musculus en Bulgarie. Genome 30:427-437.

Vigneault, G., AND E. Zouros. 1986. The genetics of asymmetrical sterility in Drosophila mojavensis and Drosophila arizonensis hybrids: Interactions between the $\mathrm{Y}$ chromosome and autosomes. Evolution 40:1160-1170.

WILliAMS, D. A. 1982. Extra-binomial variation in logistic linear models. Appl. Stat. 13:144-148.

WOMACK, J. E., M. T. DavisSon, E. M. EICHER, AND D. A. Kendall. 1977. Mapping of nucleoside phosphorylase $(\mathrm{Np}-1)$ and esterase $10(E s-10)$ on mouse chromosome 14. Biochem. Genet. 15:347355.

Zeger, S. L., AND K. M. Rezaul. 1991. Generalized linear models with random effects; a Gibbs sampling approach. J. Am. Stat. Assoc. 86:79-86.

Corresponding Editor: G. Hewitt 
Appendix. Genotype data for seven genetic loci from individual mice collected from the hybrid zone. Data for each individual is presented by locality number and given in the following order: Museum of Vertebrate Zoology identification number, sex, YB10, X1 (locus DXWas68), X2 (locus DXWag 31), Mpi-1, $\underline{\mathrm{Np}-1}, \underline{\mathrm{Eg}-10}$, and Eg-1. Symbols are as follows: $1=$ male, 2 = female, $m=\underline{k}$ musculus allele, $d=\underline{M}$. domesticus allele, $+=$ unassignable rare alleles, -- = missing data, $00=$ no data (e.g. for $\underline{\text { YB10 }}$ in females), and * = individuals whose $X-$ and $Y$ - linked sequences were determined from analysis of male and female progeny as described in the materials and methods section. Specific collecting localities for each map locality are given in Figure 1 and identification and chromosomal assignment of each locus is given in the text.

localitY $1: 169801,2,00,--,--, \mathrm{mm}, \mathrm{mm}, \mathrm{mm},-; 169982,2,00, \mathrm{~mm}, \mathrm{~mm}, \mathrm{~mm}, \mathrm{~mm}, \mathrm{~mm},--$; $169983,1, m, m, m, m m, m m, m m,--; 169984,1, m, m, m, m m, m m, m m, m m ; 172503,1, m, m, m, m m, m m$, $\mathrm{mm}, \operatorname{mm} .2$ : $196977,2,00,--,--, \operatorname{mm}, \mathrm{md}, \mathrm{mm},--; 169985,1, \mathrm{~m}, \mathrm{~m}, \mathrm{~m}, \mathrm{~mm}, \mathrm{~mm}, \mathrm{~mm},--; 169986,2$, $00, \mathrm{~mm}, \mathrm{~mm}, \mathrm{~mm}, \mathrm{~mm}, \mathrm{~mm}, \mathrm{~mm} .3: 169805,1, \mathrm{~m}, \mathrm{~m}, \mathrm{~m}, \mathrm{~mm}, \mathrm{~mm}, \mathrm{~mm}, \mathrm{~mm} .4: 172504,2,00, \mathrm{~mm}, \mathrm{~mm}, \mathrm{~mm}, \mathrm{~mm}$, $\mathrm{mm}, \mathrm{mm} ; 172505,1, \mathrm{~m}, \mathrm{~m}, \mathrm{~m}, \mathrm{~mm}, \mathrm{~mm}, \mathrm{~mm}, \mathrm{~mm} ; 172537,2,00, \mathrm{~mm}, \mathrm{~mm}, \mathrm{~mm}, \mathrm{~mm}, \mathrm{~mm}, \mathrm{~mm} ; * 173534,1, \mathrm{~m}$ ， $\mathrm{m}, \mathrm{m}, \mathrm{mm}, \mathrm{mm}, \mathrm{mm}, \mathrm{md} .5: 169802,2,00, \mathrm{~mm}, \mathrm{~mm}, \mathrm{~mm}, \mathrm{~mm}, \mathrm{~mm},--: 6 \mathrm{~A}: 172506,2,00,--,--, \mathrm{mm}, \mathrm{mm}$, $\mathrm{mm}, \mathrm{dd} .6 \mathrm{~B}: 172507,2,00, \mathrm{~mm}, \mathrm{~mm}, \mathrm{~mm}, \mathrm{~mm}, \mathrm{~mm}, \mathrm{md} ; 172508,2,00, \mathrm{~mm}, \mathrm{~mm}, \mathrm{~mm}, \mathrm{~mm}, \mathrm{~mm}, \mathrm{md} ; 172513$, $1, \mathrm{~m}, \mathrm{~m}, \mathrm{~m}, \mathrm{~mm}, \mathrm{~mm}, \mathrm{~mm}, \mathrm{~mm} ; \star 173536,1, \mathrm{~m}, \mathrm{~m}, \mathrm{~m}, \mathrm{~mm}, \mathrm{~mm}, \mathrm{~mm}, \mathrm{~mm} .6 \mathrm{c}: 172509,2,00, \mathrm{~mm}, \mathrm{~mm}, \mathrm{~mm}, \mathrm{~mm}$, $\mathrm{mm}, \mathrm{dd} ; 172510,1, \mathrm{~m}, \mathrm{~m}, \mathrm{~m}, \mathrm{~mm}, \mathrm{~mm}, \mathrm{~mm}, \mathrm{dd} .6 \mathrm{D}: 172511,2,00, \mathrm{~mm}, \mathrm{~mm}, \mathrm{~mm}, \mathrm{~mm}, \mathrm{~mm}, \mathrm{~mm} ; 172512,1$, $\mathrm{m}, \mathrm{m}, \mathrm{m}, \mathrm{mm}, \mathrm{mm}, \mathrm{mm}, \mathrm{mm} .6 \mathrm{E}: 172539,1,-,--,-, \mathrm{mm}, \mathrm{mm}, \mathrm{mm}, \mathrm{mm} ; * 172541,1, \mathrm{~m}, \mathrm{~m}, \mathrm{~m}, \mathrm{~mm}, \mathrm{~mm}, \mathrm{~mm}, \mathrm{dd} ;$ $172542,2,00,--,--, \mathrm{mm}, \mathrm{mm}, \mathrm{mm}, \mathrm{mm} ; 172543,2,00,--,--, \mathrm{mm}, \mathrm{mm}, \mathrm{mm}, \mathrm{dd} ; 172544,2,00, \mathrm{~mm}$, $\mathrm{mm}, \mathrm{mm}, \mathrm{mm}, \mathrm{mm}, \mathrm{md} ; 172545,2,00, \mathrm{~mm}, \mathrm{~mm}, \mathrm{~mm}, \mathrm{~mm}, \mathrm{~mm}, \mathrm{~mm} ; * 172538,1, \mathrm{~m}, \mathrm{~m}, \mathrm{~m},--,--,--,--.7$ : $169804,1, m, m, m, m m, m m, \operatorname{mm}, \operatorname{mm} .8: 169813,2,00, \mathrm{~mm}, \mathrm{~mm}, \mathrm{~mm}, \mathrm{~mm}, \mathrm{md}, \mathrm{mm} .9 \mathrm{~A}: 169806,1,-,-$, , $-, \mathrm{mm}, \mathrm{mm}, \mathrm{md},--; 169807,1,-,-,-, \mathrm{mm}, \mathrm{mm}, \mathrm{mm},--; 169808,2,00,--,--, \mathrm{mm}, \mathrm{mm}, \mathrm{md}$, 
$--; 169809,2,00, \mathrm{~mm}, \mathrm{~mm}, \mathrm{~mm}, \mathrm{~mm},--,--; 169810,1, \mathrm{~m}, \mathrm{~m}, \mathrm{~m}, \mathrm{~mm}, \mathrm{~mm}, \mathrm{~mm},--; 169811,2,00, \mathrm{~mm}$, $\mathrm{mm}, \mathrm{mm}, \mathrm{mm}, \mathrm{md},--; 169815,2,00,--,--, \mathrm{mm}, \mathrm{mm}, \mathrm{mm}, \mathrm{mm} ; 169816,2,00, \mathrm{~mm}, \mathrm{~mm}, \mathrm{~mm}, \mathrm{~mm}, \mathrm{md}$, $\mathrm{mm} ; 169817,2,00, \mathrm{~mm}, \mathrm{~mm}, \mathrm{~mm}, \mathrm{~mm}, \mathrm{md}, \mathrm{mm} ; 169818,2,00, \mathrm{~mm}, \mathrm{~mm}, \mathrm{~mm}, \mathrm{~mm}, \mathrm{md}, \mathrm{mm} ; 169819,2,00$, $\mathrm{mm}, \mathrm{mm}, \mathrm{mm}, \mathrm{mm}, \mathrm{md}, \mathrm{mm} ; 169820,2,00, \mathrm{~mm}, \mathrm{~mm}, \mathrm{~mm}, \mathrm{~mm}, \mathrm{md}, \mathrm{mm} ; 169977,1, \mathrm{~m}, \mathrm{~m}, \mathrm{~m}, \mathrm{~mm}, \mathrm{~mm}, \mathrm{~mm}$, $\mathrm{mm} ; 169981,2,00, \mathrm{~mm}, \mathrm{~mm},--, \mathrm{mm}, \mathrm{mm},--; 172433,2,00, \mathrm{~mm}, \mathrm{~mm}, \mathrm{~mm}, \mathrm{~mm}, \mathrm{md}, \mathrm{mm} ; 172527,1, \mathrm{~m}$, $\mathrm{m}, \mathrm{m}, \mathrm{mm}, \mathrm{mm}, \mathrm{mm}, \mathrm{mm} ; 172528,2,00, \mathrm{~mm}, \mathrm{~mm}, \mathrm{~mm}, \mathrm{~mm}, \mathrm{~mm}, \mathrm{~mm} ; 172529,2,00, \mathrm{~mm}, \mathrm{~mm}, \mathrm{~mm}, \mathrm{~mm},+\mathrm{m}, \mathrm{mm}$; *172534, $1, m, m, m, m m, m d, m m, m m ; * 172535,1, m, m, m, m m, m m, m d, m m ; 172536,2,00, m m, m m$, $\mathrm{mm}, \mathrm{mm}, \mathrm{md}, \mathrm{mm} .98: 169814,1, \mathrm{~m}, \mathrm{~m}, \mathrm{~m}, \mathrm{~mm}, \mathrm{md}, \mathrm{mm}, \mathrm{mm} .10: 169812,1, \mathrm{~m}, \mathrm{~m}, \mathrm{~m}, \mathrm{~mm}, \mathrm{md}, \mathrm{mm},--$ 11A: $169795,2,00, \mathrm{~mm}, \mathrm{~mm}, \mathrm{~mm}, \mathrm{md}, \mathrm{mm}, \mathrm{mm} .118: 169796,1,-,-,-, \mathrm{mm}, \mathrm{mm}, \mathrm{mm}, \mathrm{dd} .12$ : 169915 , $1, m, m, m, m m, m m, m m, m m ; 169916,2,00, m m, m m, m m, m d, m m, ~ m d .13: 169967,2,00, m m, m m, ~ m m$, $\mathrm{md}, \mathrm{mm}, \mathrm{mm} ; 169978,1, \mathrm{~m}, \mathrm{~m}, \mathrm{~m}, \mathrm{~mm}, \mathrm{~mm}, \mathrm{~mm}, \mathrm{~mm} ; 169979,2,00, \mathrm{~mm}, \mathrm{~mm}, \mathrm{~mm}, \mathrm{md}, \mathrm{md}, \mathrm{mm} ; 169980,1$, $\mathrm{m}, \mathrm{m}, \mathrm{d}, \mathrm{mm}, \mathrm{mm}, \mathrm{md}, \mathrm{mm} ; 172478,2,00, \mathrm{~mm}, \mathrm{~mm}, \mathrm{~mm}, \mathrm{md}, \mathrm{md}, \mathrm{mm} ; 172479,2,00, \mathrm{~mm}, \mathrm{~mm}, \mathrm{~mm}, \mathrm{~mm}, \mathrm{md}$, $\mathrm{mm} ; 172480,2,00, \mathrm{~mm}, \mathrm{dd}, \mathrm{mm}, \mathrm{mm}, \mathrm{mm}, \mathrm{mm} ; * 172481,1, \mathrm{~m}, \mathrm{~m}, \mathrm{~d}, \mathrm{~mm}, \mathrm{~mm}, \mathrm{dd}, \mathrm{mm} ; * 173535,1, \mathrm{~m}, \mathrm{~m}$, $\mathrm{m}, \mathrm{mm}, \mathrm{mm}, \mathrm{mm}, \mathrm{mm} ; 172496,2,00,--, \mathrm{mm}, \mathrm{mm}, \mathrm{mm}, \mathrm{mm}, \mathrm{mm} ; 172497,2,00, \mathrm{~mm}, \mathrm{~mm}, \mathrm{~mm}, \mathrm{md}, \mathrm{md}, \mathrm{mm}$; $\star 172498,1, m, m, d, m m, m m, m m, m m ; 172554,2,00, m m, m d, m m, m m, m m, m m .14: 169792,2,00, m m$, $\mathrm{mm}, \mathrm{md}, \mathrm{mm}, \mathrm{mm}, \mathrm{md} ; 169803,1, \mathrm{~m}, \mathrm{~m}, \mathrm{~m}, \mathrm{md}, \mathrm{md}, \mathrm{mm}, \mathrm{md} ; 169990,1, \mathrm{~m}, \mathrm{~m}, \mathrm{~m}, \mathrm{~mm}, \mathrm{dd}, \mathrm{md}, \mathrm{mm} ; 169991$, 2,00, mm , mm, mm , md, md, $\mathrm{mm} .15 \mathrm{~A}: 169824,2,00, \mathrm{~mm}, \mathrm{~mm}, \mathrm{~mm}, \mathrm{~mm}, \mathrm{md}, \mathrm{md} ; 169825,2,00, \mathrm{~mm}, \mathrm{~mm}$, $\mathrm{mm}, \mathrm{md}, \mathrm{mm}, \mathrm{md} ; 169826,2,00, \mathrm{~mm}, \mathrm{md}, \mathrm{mm}, \mathrm{dd}, \mathrm{md}, \mathrm{mm} ; 169827,2,00, \mathrm{~mm}, \mathrm{~mm}, \mathrm{~mm}, \mathrm{md}, \mathrm{md}, \mathrm{mm}$; $169772,2,00, \mathrm{~mm}, \mathrm{~mm}, \mathrm{~mm}, \mathrm{~mm}, \mathrm{~mm}, \mathrm{~mm} ; 169797,2,00, \mathrm{~mm}, \mathrm{~mm}, \mathrm{~mm}, \mathrm{~mm}, \mathrm{md}, \mathrm{mm} ; 169798,1, \mathrm{~m}, \mathrm{~m}, \mathrm{~m}$, $\mathrm{mm}, \mathrm{md}, \mathrm{mm}, \mathrm{md} ; 169799,1, \mathrm{~m}, \mathrm{~m}, \mathrm{~m}, \mathrm{~mm}, \mathrm{~mm}, \mathrm{md}, \mathrm{md} ; 169800,2,00, \mathrm{~mm}, \mathrm{~mm}, \mathrm{~mm}, \mathrm{md}, \mathrm{mm},--; 169951$,

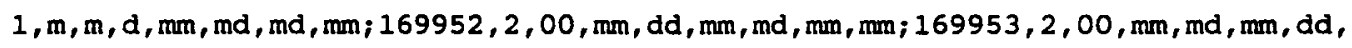
$\mathrm{md}, \mathrm{mm} ; 169913,1, \mathrm{~m}, \mathrm{~m}, \mathrm{~m}, \mathrm{~mm}, \mathrm{~mm}, \mathrm{dd}, \mathrm{mm} ; 169954,1, \mathrm{~m}, \mathrm{~m}, \mathrm{~d}, \mathrm{~mm}, \mathrm{dd}, \mathrm{mm}, \mathrm{m}+; 169955,2,00, \mathrm{~mm}$, $\mathrm{dd}, \mathrm{mm}, \mathrm{dd}, \mathrm{mm}, \mathrm{mm} ; 169956,1, \mathrm{~m}, \mathrm{~m}, \mathrm{~m}, \mathrm{~mm}, \mathrm{md}, \mathrm{md},--; 169957,1, \mathrm{~m}, \mathrm{~m}, \mathrm{~m}, \mathrm{~mm}, \mathrm{~mm},--,--; 169914$, $1, m, m, m, m m, m m, m d,--; 172474,2,00, m m, m d, m m, m m, d d, m m ; * 172475,1, m, m, m, m m, d d, m d$, $\mathrm{mm} ; * 172476,1, m, m, m, m m, m m, d d, m m ; 172520,1, m, m, d, m m, m d, m d, m m .15 B: 169790,1, m, m$, $\mathrm{m}, \mathrm{mm}, \mathrm{md}, \mathrm{mm}, \mathrm{mm} .16: 169973,2,00, \mathrm{~mm}, \mathrm{~mm}, \mathrm{~mm}, \mathrm{md}, \mathrm{mm}, \mathrm{dd} ; 169987,1, \mathrm{~m}, \mathrm{~m}, \mathrm{~m}, \mathrm{~mm}, \mathrm{dd}, \mathrm{dd}, \mathrm{dd}$; 
$172530,2,00, \mathrm{~mm}, \mathrm{~mm}, \mathrm{~mm}, \mathrm{md}, \mathrm{md}, \mathrm{mm} ; 172531,2,00, \mathrm{~mm}, \mathrm{~mm}, \mathrm{~mm}, \mathrm{md}, \mathrm{dd}, \mathrm{md} ; 172557,2,00, \mathrm{~mm}$, $\mathrm{mm}, \mathrm{mm}, \mathrm{mm}, \mathrm{mm}, \mathrm{dd} .17: 169964,2,00, \mathrm{md}, \mathrm{mm}, \mathrm{mm}, \mathrm{mm}, \mathrm{md}, \mathrm{mm} ; 169965,2,00, \mathrm{~mm}, \mathrm{~mm}, \mathrm{~mm}, \mathrm{~mm}, \mathrm{dd}$, $\mathrm{mm} ; 169966,1, \mathrm{~m}, \mathrm{~m}, \mathrm{~m}, \mathrm{~mm}, \mathrm{md}, \mathrm{md}, \mathrm{m}+; 169969,2,00, \mathrm{~mm}, \mathrm{~mm}, \mathrm{~mm}, \mathrm{~mm}, \mathrm{md}, \mathrm{mm} ; 169970,2,00, \mathrm{~mm}$, $\mathrm{mm}, \mathrm{mm}, \mathrm{mm}, \mathrm{dd}, \mathrm{mm} ; 169975,2,00, \mathrm{md}, \mathrm{mm}, \mathrm{mm}, \mathrm{md}, \mathrm{dd}, \mathrm{dd} ; 169976,1, \mathrm{~m}, \mathrm{~m}, \mathrm{~m}, \mathrm{~mm}, \mathrm{~mm}, \mathrm{~mm}, \mathrm{~mm}$; $169992,2,00, \mathrm{~mm}, \mathrm{~mm}, \mathrm{~mm}, \mathrm{~mm}, \mathrm{md}, \mathrm{m}+; 169940,2,00, \mathrm{~mm}, \mathrm{~mm}, \mathrm{md}, \mathrm{md}, \mathrm{md},++; 173541,2,00, \mathrm{md}$, $\mathrm{mm}, \mathrm{mm}, \mathrm{md}, \mathrm{dd}, \mathrm{mm} ; 172472,2,00, \mathrm{~mm}, \mathrm{~mm}, \mathrm{~mm}, \mathrm{md}, \mathrm{dd}, \mathrm{mm} ; 172473,2,00, \mathrm{~mm}, \mathrm{~mm}, \mathrm{md}, \mathrm{md}, \mathrm{md}, \mathrm{md}$; $172524,2,00, \mathrm{md}, \mathrm{mm}, \mathrm{mm}, \mathrm{mm}, \mathrm{dd}, \mathrm{mm} ; 172525,2,00, \mathrm{md}, \mathrm{mm}, \mathrm{mm}, \mathrm{mm}, \mathrm{md}, \mathrm{mm} ; 172526,2,00, \mathrm{~mm}$, $m m, m m, m m, d d, m m ; 172553,1, m, d, m, m m, m d, d d, m m ; 173540,1, d, d, m, m d, m d, m d, m m .18:$ $169971,1, \mathrm{~m}, \mathrm{~d}, \mathrm{~m}, \mathrm{md}, \mathrm{mm}, \mathrm{mm}, \mathrm{dd} ; 169972,2,00, \mathrm{md}, \mathrm{md}, \mathrm{dd}, \mathrm{mm}, \mathrm{mm}, \mathrm{md} ; 172521,2,00, \mathrm{~mm}, \mathrm{md}$, $\mathrm{mm}, \mathrm{md}, \mathrm{mm}, \mathrm{md} ; 172522,1, \mathrm{~m}, \mathrm{~m}, \mathrm{~m}, \mathrm{dd}, \mathrm{mm}, \mathrm{mm}, \mathrm{md} ; 172523,1, \mathrm{~m}, \mathrm{~m}, \mathrm{~m}, \mathrm{~mm}, \mathrm{~mm}, \mathrm{~mm},--.19: 169828$, 2,00, md, dd, mm, dd, md, mm; 169791,2,00, md, md, $+d, m d, m m$, md $; 169829,1, d, m, m, m d, m d$, $\mathrm{mm}, \mathrm{md} ; 169840,2,00, \mathrm{~mm}, \mathrm{~mm}, \mathrm{~mm}, \mathrm{dd}, \mathrm{mm}, \mathrm{md} ; 169841,2,00, \mathrm{md}, \mathrm{dd}, \mathrm{mm}, \mathrm{dd}, \mathrm{mm}, \mathrm{dd} ; 169764,1$, $d, m, m, d d, d d, m m, d d ; 169842,2,00,--,--, m m, m d, m m, m d ; 169843,2,00,--,--, d d, d d, m m$, md; $169770,2,00, \mathrm{~mm}, \mathrm{md}, \mathrm{dd}, \mathrm{dd}, \mathrm{mm}, \mathrm{dd} ; 169771,2,00,--,--, \mathrm{mm}, \mathrm{dd}, \mathrm{mm}, \mathrm{md} ; 169793,2,00$, $--,--, \mathrm{md}, \mathrm{mm}, \mathrm{mm}, \mathrm{mm} ; 169794,2,00,--,--, \mathrm{dd}, \mathrm{md}, \mathrm{mm}, \mathrm{dd} ; 169917,2,00, \mathrm{dd}, \mathrm{md}, \mathrm{md}, \mathrm{dd}, \mathrm{md}$, dd; $169918,2,00, \mathrm{~mm}, \mathrm{md}, \mathrm{md}, \mathrm{md}, \mathrm{mm}, \mathrm{md} ; 169958,2,00, \mathrm{dd}, \mathrm{md}, \mathrm{dd}, \mathrm{dd}, \mathrm{mm}, \mathrm{md} ; 169919,2,00$, md, dd, md, md, mm, md; 169959, 2,00, md, md, dd, md, mm, dd ; 169960, 1, -, -, - , md, dd, md, -- ; 169920, 1, d, d, m, md, dd, md, md; 169921,2,00,mm, mm, md, dd, md, dd; 169922, 2, 00, md, md, md, dd, mm, md; 169961, 2, 00, dd, md, dd, dd, dd, md; 169962, 1, d, d, d, dd, md, mm, dd; 169963, 1, m, d, d, md, md, mm, dd; 169968, 2,00, dd, dd, md, dd, mm, mm; 169932, 2, 00, md, md, md, dd, mm, -- ; 169933,1, d, m, d, mm, dd, mm, --;169938, 2, 00, md, md, mm, dd, md, dd; 169988, 2,00, dd, md, mm, dd, md; mm; 169939,2 , md, md, md, md, mm, md; $169989, m, d, d, d, d d, d d, m d$, $--; \star 172421,1, d, d, d, d d, d d, m d, d d ; 172422,1, d, d, d, m m, d d, m m, m d ; 172423,2,00, d d, d d$, md, md, mm, dd; $172424,2,00, \mathrm{dd}, \mathrm{dd}, \mathrm{mm}, \mathrm{dd}, \mathrm{md}, \mathrm{md} ; 172426,2,00, \mathrm{md}, \mathrm{md}, \mathrm{mm}, \mathrm{dd}, \mathrm{mm}, \mathrm{dd}$; $172427,2,00, \mathrm{dd}, \mathrm{md}, \mathrm{md}, \mathrm{dd}, \mathrm{mm}, \mathrm{dd} ; 172428,2,00, \mathrm{md}, \mathrm{md}, \mathrm{dd}, \mathrm{dd}, \mathrm{dd}, \mathrm{md} ; * 172429,1, \mathrm{~d}, \mathrm{~d}, \mathrm{~d}$, $\mathrm{mm}, \mathrm{dd}, \mathrm{mm}, \mathrm{dd} ; 172430,2,00, \mathrm{dd}, \mathrm{dd}, \mathrm{dd}, \mathrm{dd}, \mathrm{mm}, \mathrm{mm} ;{ }^{\star} 172431,1, \mathrm{~d}, \mathrm{~d}, \mathrm{~m}, \mathrm{dd}, \mathrm{dd}, \mathrm{md}, \mathrm{md}$; 
$172432,2,00, \mathrm{dd}, \mathrm{md}, \mathrm{md}, \mathrm{dd}, \mathrm{md}, \mathrm{md} ; 172443,2,00, \mathrm{~mm}, \mathrm{md}, \mathrm{md}, \mathrm{dd}, \mathrm{dd}, \mathrm{mm} ; 172444,2,00, \mathrm{md}$, $\mathrm{dd}, \mathrm{md}, \mathrm{dd}, \mathrm{md}, \mathrm{dd} ; * 172482,1, \mathrm{~d}, \mathrm{~m}, \mathrm{~m}, \mathrm{md}, \mathrm{dd}, \mathrm{mm}, \mathrm{md} ; * 172483,1, \mathrm{~d}, \mathrm{~m}, \mathrm{~m}, \mathrm{md}, \mathrm{dd}, \mathrm{md}, \mathrm{dd}$; $172484,1, m, d, d, m d, d d, d d, m d ; 172485,2,00,--,--, m d, d d, m m, d d ; 172487,2,00, m d, m d$, $\mathrm{md}, \mathrm{md}, \mathrm{md}, \mathrm{md} ; 172488,2,00$, md, dd , md, dd, md, dd; $172489,2,00,--,--, \mathrm{mm}, \mathrm{md}, \mathrm{mm}, \mathrm{md}$; $172490,2,00, \mathrm{~mm}, \mathrm{~mm}, \mathrm{dd}, \mathrm{dd}, \mathrm{md}, \mathrm{md} ; 172492,2,00, \mathrm{md}, \mathrm{dd}, \mathrm{md}, \mathrm{dd}, \mathrm{md}, \mathrm{md} ; 172493,2$, mm, mm, md , md, mm , dd; *172494, 1,d, -,m, dd, md, md, md; 173538, 1,- , - , - , dd, md, md, md; 172495 , 1, $d, m, m, m d, m d, m m, m d ; 172514,2,00, m d$, md , md, dd, md, dd ; 172515, 2,00, md, md, dd, dd, $\mathrm{mm}, \mathrm{dd} ; 172516,2,00, \mathrm{md}, \mathrm{mm}, \mathrm{md}, \mathrm{md}, \mathrm{mm}, \mathrm{md} ; 172517,1, \mathrm{~d}, \mathrm{~m}, \mathrm{~d}, \mathrm{dd}, \mathrm{md}, \mathrm{mm}, \mathrm{dd} ; * 172547,1, \mathrm{~d}$, $\mathrm{m}, \mathrm{d}, \mathrm{md}, \mathrm{md}, \mathrm{mm}, \mathrm{dd} ; 172548,2,00, \mathrm{md}, \mathrm{dd}, \mathrm{md}, \mathrm{dd}, \mathrm{mm}, \mathrm{md} ; 172549,2,00,--, \mathrm{md}, \mathrm{dd}, \mathrm{md}, \mathrm{md}, \mathrm{mm}$; $172550,2,00, \mathrm{dd}, \mathrm{dd}, \mathrm{dd}, \mathrm{dd}, \mathrm{md}, \mathrm{dd} ; 172551,2,00, \mathrm{~mm}, \mathrm{~mm}, \mathrm{~mm}, \mathrm{~mm}, \mathrm{~mm}, \mathrm{dd} ; 173539,2,00, \mathrm{md}$,

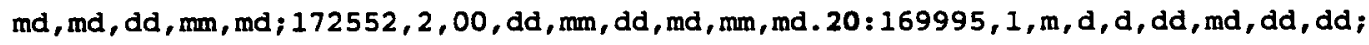
169934, 2, 00, dd, dd, md, dd, dd, dd; 169937, 2, 00, dd, dd, dd, mm, dd, dd ; 169974, 1, m, d, d, dd, dd, dd, dd; 172466,2 , 00, -- ,-- , dd, md, dd, dd; 172467,2 , 00, dd , dd , dd, dd , dd, dd; $\star 172468,1, d, d, d, d d, d d, d d, d d ; * 172469,1, d, d, d, d d, d d, d d, d d ; * 172470,1, d, d, d, d d$, dd , dd, dd; $* 172471,1, d, d, d, m d, m d, d d, d d ; 172518,1, d, d, d, d d, d d, d d, d d ; 172519,1, d$, d, d, dd, dd, dd, dd. $21: 169839,1, m, d, d, d d, d d, d d, d d .22: 169769,1, d, d, m, d d, d d, d d, d d$. 23 : $169935,2,00,--,--, d d, m d, d d, d d ; 169936,1, d, d, d, d d, d d, m d, d d ; 172445,2$, $00, d d$, dd, dd, dd, dd, dd; 172446, 2,00, dd , dd, md, dd , dd, md; 172447,2 , 00, dd, dd, dd, dd, dd , md; $172448,1, d, d, d, m d, d d, d d, m d ; 172456,2,00, d d, d d, d d, d d, d d, m d ; 173544,2,00, d d, d d$, md , dd, dd, md ; *173545, 1, d, d, d, mm, dd, dd, dd . 24:169833, 2, 00, dd, dd, dd, dd, md, md; $169834,1, d, d, d, d d, d d$, md , md; $169835,1, d, d, d, d d, d d, d d, d d ; 169836,1, d, d, d, d d, d d$, md, dd; $169837,1, d, d, d, d d, d d$, md, dd ; 169838, 1, d, d, d, dd, dd, dd, dd ; 169763, 1, d, d, $d, d d, d d, d d$, md ; 169778, 2, 00, dd, dd, dd, dd, md, md; 169779, 2, 00, dd, dd, dd, dd, md, dd; $169780,1, d, d, d, d d, d d, m d, d d ; 169896,2,00, d d, d d, d d, d d, m d, d d ; 169897,1, d, d, d, d d$, dd, md , dd; 169898,2 , 00, dd, --,++, dd, dd, dd; $169899,2,00$, dd , dd , dd, dd , dd , dd;

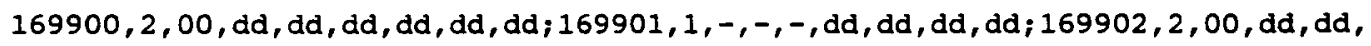


dd , dd , mm , dd ; 169903, 1,- ,- ,- , d+ , dd , dd, --;169904, 1, d, d, d, dd, dd , md, dd ; 169905 , 1, d, d, d, dd , dd , md, dd ; 169906, 2, 00, dd , dd , dd , dd , dd , dd ; 169907, 1, d, d, d, dd , dd , md, $d d ; 169908,1, d, d, d, d d, d d, m d, d d ; 172414,2,00, d d, d d, d d, d d,+d, d d ; \star 172415,1, d, d, d$, $d d, d d, d d, d d ; * 172416,1, d, d, d, d d, d d, m d, d d ; 172417,2,00,--,--, d d, d d, m d, d d$; $172436,2,00,--,--$, dd , dd, md, dd; $172437,2,00$, dd , dd, dd , dd , dd , dd ; $172438,2,00$, dd, $d d, d d, d d, d d, d d ; 172439,2,00, d d, d d, d d, d d, d d, d d ; 172440,2$, 00, dd , dd , dd, dd, dd, dd; $172461,2,00, d d, d d, d d, d d, m d, d d ; 172462,1, d, d, d, d d, d d, m d, d d ; * 172463,1, d, d, d, d d$, $d d, d d, d d ; * 172464,1, d, d, d, d d, d d, d d, d d ; * 173546,1, d, d, d, d d, d d, d d, d d ; * 172465,1$, $d, d, d, d d, d d, d d, d d .25: 169831,1, d, d, d, d d, d d, d d, d d ; 169832,2,00, d d, d d, d d, d d, d d$, $d d ; 169909,2,00, d d, d d, d d, d d, d d,--; 169910,1, d, d, d, d d, d d, d d, d d ; 169911,1, d, d, d$, dd, dd , dd , dd; $169912,2,00,--, d d, d d, d d, d d, d d ; 169930,2,00, d d, d d, d d, d d, d d, d d ;$ $169931,2,00, \mathrm{dd}, \mathrm{dd}, \mathrm{dd}, \mathrm{dd}, \mathrm{md},--; * 172418,1, \mathrm{~d}, \mathrm{~d}, \mathrm{~d}, \mathrm{dd}, \mathrm{dd}, \mathrm{dd}, \mathrm{dd} ; 172419,2,00, \mathrm{dd}, \mathrm{dd}$, $d d, d d, d d, d d ; 172441,1, d, d, d, d d, d d, d d, d d ; 172442,2,00, d d, d d, d d, d d, d d, m d$; $173542,2,00, d d, d d, d d, d d, d d, d d ; * 173543,1, d, d, d, d d, d d, d d, d d ; * 172458,1, d, d, d$, $d d, d d, d d, d d ; 172459,1, d, d, d, d d, d d, d d, d d ; 172460,1, d, d, d, d d, d d, d d, d d$.

26A: $172499,2,00, d d, d d, d d, d d, d d, d d ; 172500,1, d, d, d, d d, d d, d d, d d ; 172532,2,00, d d$, dd, dd, dd , dd, dd. 26B: 173548, 2,00, dd, dd, dd, dd, dd, dd. $27: \star 172558,1$, d, d, d, dd, dd, $d d, d d ; * 173547,1, d, d, d, d d, d d, d d, d d ; 172501,2$, 00, dd , dd , dd , dd , dd , dd. 28A: 172502 , $2,00, d d, d d, d d, d d, d d, d d ; 172533,1, d, d, d, d d, d d, d d, d d .28 B: 173549,2,00, d d, d d, d d$, $d d, d d, d d ; 172559,2,00, d d, d d, d d, d d, d d, d d ; 172560,2$, 00, dd , dd , dd , dd , dd , dd . 29 : $169765,2,00, d d, d d, d d, d d, d d, d d ; 169923,1, d, d, d, d d, d d, d d, d d ; 169924,1, d, d, d, d d$, dd , dd , dd; 169925, 2, 00, dd , dd , dd, dd , dd , dd; 169926, 2, 00, dd , dd , dd, dd , dd , dd; 169927, $2,00, d d, d d, d d, d d, d d, d d ; 172449,2,00, d d, d d, d d, d d, d d, d d ; 172450,1, d, d, d, d d, d d$, dd , dd. 30A : 169766, 1, d, d, d, dd , dd , dd , dd; 169767, 2,00, dd, dd , dd , dd , dd , dd; 169768, 2 , 00, dd, dd, dd, dd, dd, dd. 308: 169928, 2,00, dd, dd, dd, dd, dd, dd; 169929, 1, d, d, d,

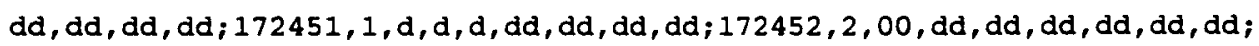
$172453,2,00, d d, d d, d d, d d, d d, d d ;-, 2,00,--,--, d d, d d, d d, d d ; \star 172454,1, d, d, d, d d$, $d d, d d, d d ; * 172455,1, d, d, d, d d, d d, d d, d d$. 